\title{
Nowhere to Now-here: Empowering Children to Reimagine Bully Prevention at Schools Using Critical Design Fiction
}

\author{
Exploring the Potential of Participatory, Empowering Design Fiction in Collaboration with Children
}

\author{
Leena Ventä-Olkkonen* \\ University of Oulu \\ Oulu, Finland \\ leena.venta-olkkonen@oulu.fi \\ Tonja Molin-Juustila \\ University of Oulu \\ Oulu, Finland \\ tonja.molin-juustila@oulu.fi
}

\author{
Netta Iivari \\ University of Oulu \\ Oulu, Finland \\ netta.iivari@oulu.fi \\ Kari Kuutti \\ University of Oulu \\ Oulu, Finland \\ kari.kuutti@oulu.fi
}

\author{
Sumita Sharma \\ University of Oulu \\ Oulu, Finland \\ sumita.sharma@oulu.fi \\ Nina Juustila-Cevirel \\ University of Oulu \\ Oulu, Finland \\ nina.juustila-cevirel@oulu.fi
}

\author{
Essi Kinnunen \\ University of Oulu \\ Oulu, Finland \\ essi.kinnunen@oulu.fi
}

\author{
Jenni Holappa \\ University of Oulu \\ Oulu, Finland \\ jenni.holappa@oulu.fi
}

\begin{abstract}
Bullying is a problem concerning us all, especially our children. Human Computer Interaction (HCI) has invited children to tackle this problem through design and technology. However, yet there is limited research including critical engagement with the topic, even if the critical agenda is arousing increasing interest in HCI. Design fiction has shown potential in addressing critical concerns. However, albeit design fiction has entered HCI method repertoire already some time ago, it is an ambiguous concept with multiple meanings and usages. We map and articulate some of this variety: fascinating, future-oriented, and provocative studies are identified, while also a lack of critical design fiction, aiming at empowerment of the power-weak. We contribute by exploring such kind of design fiction in collaboration with children to tackle the problem of bullying. We scrutinize our participatory and empowering design fiction process and outcomes and discuss their implications for $\mathrm{HCI}$ research and design fiction practice.
\end{abstract}

\section{CCS CONCEPTS}

- Human-centered computing $\rightarrow$ Empirical studies in interaction design; $\bullet$ Social and professional topics $\rightarrow \mathrm{K}-12$ education.

\section{KEYWORDS}

Children, Bullying, Design fiction, Critical, Empowerment

CC $९$ (7)
This work is licensed under a Creative Common
4.0 License.
DIS '21, fune 28-fuly 2, 2021, Virtual Event, USA
(C) 2021 Copyright held by the owner/author(s).
ACM ISBN 978-1-4503-8476-6/21/06.
https://doi.org/10.1145/3461778.3462044

\section{ACM Reference Format:}

Leena Ventä-Olkkonen, Netta Iivari, Sumita Sharma, Tonja Molin-Juustila, Kari Kuutti, Nina Juustila-Cevirel, Essi Kinnunen, and Jenni Holappa. 2021. Nowhere to Now-here: Empowering Children to Reimagine Bully Prevention at Schools Using Critical Design Fiction: Exploring the Potential of Participatory, Empowering Design Fiction in Collaboration with Children. In Designing Interactive Systems Conference 2021 (DIS '21), June 28-July 2, 2021, Virtual Event, USA. ACM, New York, NY, USA, 15 pages. https://doi.org/10.1145/3461778.3462044

\section{INTRODUCTION}

Bullying is a troublesome, widespread, and serious problem concerning us all, from small children to adults and the elderly. Human Computer Interaction (HCI) research, among a multitude of other disciplines, has recognized the seriousness of this problem and reacted against it through design and technology [41]. Within this stream of research, there is particular focus on children: Child Computer Interaction (CCI) researchers have addressed the problem in collaboration with children, developing digital tools for preventing or reducing bullying and/or engaging with children in Participatory Design (PD) process for the purpose [3, 9, 22, 29, 30, 51, 58, 63, 64]. Albeit valuable work, there are limitations in the existing research addressing bullying in collaboration with children (for a review, see [41]). Particularly we identify a lack of critical engagement, inspired by the critical tradition, aiming at empowering the oppressed, marginalized, dominated or power-weak. In this study, we explore how to encourage critical engagement of children to address the problem of bullying through design and technology.

The critical agenda ${ }^{1}$ is arousing increasing interest in HCI, not only relating to children and the topic of bullying. Actually, critical concerns in computing can be dated back to the 1960s when Scandinavian PD tradition started highlighting the need for worker and

\footnotetext{
${ }^{1}$ The critical agenda is characterized by "an intention to change the status quo, overcome injustice and alienation, and promote emancipation" [68]. Hence, critical researchers should aim at changing how things are; emancipatory interests characterize critical research, [2, 16, 67]
} 
union participation in the development of computer systems at the workplace, having a strong Marxist flavor, and advocating for workplace democracy (e.g. [27]). During the years, political concerns and critical voices have become silenced for a couple of decades, but now they are back. Today, one can identify a revitalized interest in power and politics around design and technology. There is an increasing acknowledgement that design and technology are not neutral or value free, but they may have a variety of consequences both good and bad. HCI is seriously starting to tackle this emergent topic.

Design fiction has potential for a critical engagement with design and technology $[39,40]$. Design fiction has aroused interest in $\mathrm{HCI}$ already for some time: it has been utilized for envisioning and exploring alternative futures, for collaborating with stakeholders as well as for critique, questioning and addressing critical concerns (e.g., $[16,69,71])$. Design fiction can be connected with the method repertoire of design research tradition, especially with speculative $[19,20,69,71]$ and critical design $[21,68]$ but also with PD and user-centered design including future scenarios [16, 23, 49]. Due to these different origins and traditions, it is no surprise that design fiction is an ambiguous concept with multiple meanings and usages $[5,16]$. Some background influences connect with the critical tradition, but obviously not all and there are vast differences within The PD tradition has embraced critical theory in its early efforts for workplace democracy and worker empowerment, while the contemporary interpretations do not necessarily acknowledge the critical origins (e.g.,[6]). Critical design has as well been criticized to rely on critical research tradition in a very limited sense [40]. Even if it is contrasted with mainstream design, and even if critical tradition is referred to in the original texts, critical tradition does not play a significant role within critical design, which instead, similarly to design fiction, rather represents a future-oriented design tradition that can be labeled as design avant-garde [39]. A lot of recent work on design fiction links with this genre, similarly to reflective design $[4,66]$, and speculative design $[48,69]$ : they are used to consider speculative futures and alternative presents, explore alternative values, provoke the audience and/or criticize current practices and technology. However, alternative interpretations of design fiction exist as well. In this paper, we map and articulate some of this variety.

Moreover, we contribute by exploring some yet less explored forms of critical design fiction, i.e., participatory and empowering design fiction, in collaboration with children. The HCI research, and particularly CCI research has recently recognized the value of critical research and design and started to engage with the design research method repertoire. CCI research has advocated the empowerment of children through design and technology since its inception, inspired by the PD tradition (e.g. [[39]); however, these studies do not necessarily engage at all with the critical tradition. Then again, some CCI studies explicitly rely on the Scandinavian PD tradition and underscore children's empowerment to drive technology development and to critically reflect on the digitalization of our society and everyday life (e.g., [24, 37, 44]). There are also recent CCI studies that explicitly rely on critical research tradition, addressing the topics of marginalization, domination, oppression, and exclusion of children (e.g. [26, 34, 38, 65]. However, the CCI literature has not much utilized speculative, reflective or design fiction method repertoire from HCI and design research traditions yet, even if their potential for CCI research has already been noted [40]. So far, we found only one study relying on critical and reflective design with children [52] and one conducting agonistic participatory design with children [24].

We consider these approaches are needed to address the problem of bullying specifically as the problem itself is wicked (see e.g.[59]): it is power-laden, multifold, troublesome, complex, widespread as well as difficult if not even impossible to solve. While we acknowledge that digital technologies and design-based approaches by no means can solve this problem alone, as several different disciplines are needed to address this psychosocial problem, we maintain that by using an approach which combines critical design fiction with a participatory, empowering stance we may create a context in which children can at least feel safe and empowered to jointly imagine a world without bullying, i.e. envision a solution-focused desired future with favorable behaviors (see [76]) addressing this confusing and oftentimes even conflicting topic (considering bullying and being bullied as the opposites of the same coin) in their lives. Hence, we explore the potential of participatory, empowering design fiction in collaboration with children to tackle the problem of bullying at school in a research project that explores critical design and critical making with children, and critically scrutinize the outcomes of such an endeavor.

The paper is structured as follows. Section two reviews and maps existing $\mathrm{HCI}$ and CCI research on design fiction, while section three introduces the research design involved in this study. Section four presents the empirical insights while section five discusses their implications. Section six concludes the paper.

\section{DIFFERENT DISCOURSES ON DESIGN FICTION}

\subsection{Analytic lens on discourses on design fiction}

Our mapping of the literature on design fiction is inspired by the work by Deetz [15], who suggests the dimensions of local/emergent versus elite/a priori and consensus versus dissensus as useful distinctions [15] when mapping discourses in the academic literature. The distinction between local/emergent and elite/a priori highlights the origins of the research concepts and problem statements: whether they emerge locally or are defined by researchers a priori [15]. In the context of design fiction, this can be used to distinguish different sources of ideas and authority: whether the ideas are defined or generated by theory and/or by the elite/experts (researchers, professionals, artists) or whether they are created locally among the participants and their collaboration and meanings making. The distinction between consensus and dissensus concerns the relation of research to the existing social order: it may rely on "a dominant set of structurings of knowledge" within organizations, a research community, or society (consensus), while it may also "work to disrupt these structurings" (dissensus), in which case the researcher aims at challenging the maintenance of order and domination of people [17]. This distinction can also be applied in our case: design fiction may be used within "a dominant set of structurings of knowledge" or alternatively it can be used to "to disrupt these structurings". 
However, the consensus/dissensus distinction needs to be enriched by certain notions, as it neglects the more active role of making a change that critical research can and should have. Critical research does involve critiquing, for instance, in critical research one should deconstruct discourses' inscriptions that emphasize and serve some groups and individuals while neglecting or exploiting others [2], however critical research should not only critique the status quo but emancipatory interests should always characterize critical research [16, 67]. In design fiction, one can easily identify critique: speculative futures and alternative presents are constructed with the aim to de-construct, to provoke the audience or to criticize current practices and technology. However, less can be found on design fiction serving emancipatory interests in serious sense.

The notion of the ethics of research [35], originally in [14] helps further highlight diversity in design fiction. The ethics of research refers to the role and value of research. Applied to our context, the role of design fiction can be means-ends oriented, in which case design fiction aims at "providing means knowledge for achieving certain ends without questioning the legitimacy of the ends" [35], while design fiction within the critical approach stresses "critical imperative: the identification and removal of domination and ideological practice" [14]. Value of the research refers to the issue of whose interests research serves [35]: design fiction may be used to serve the needs of academia, business/management, or the oppressed/labor. Based on these distinctions, we have developed a framework for revealing and mapping diversity in design fiction

\subsection{Different discourses on design fiction}

We argue that design fiction (discourse ${ }^{2}$ ) can rely on local/emergent or elitist/a priori ideas or authority and aim at consensus or dissensus in relation to the existing social order, acknowledging within the dissensus approach both critique and empowerment. In the case of the consensus approach, design fiction may aim at serving academia and/or business/management, whereas in the case of the dissensus discourse, serving the academia might be common while serving the oppressed should be pivotal. Figure 1 maps diversity in design fiction and identifies some representative examples of design fiction.

2.2.1 Consensus design fiction. This form of design fiction aims at imagining and exploring (alternative) digital futures without seriously aiming at disrupting the existing social order. Within the expert led approach, for example Ylipulli et al. [74] explore future hybrid cities through anthropological design fiction created by researchers and professional writers, seemingly mostly aiming at serving the academia [74]. Within the participant led approach, for example Prost et al. [60] and Nägele et al. [57] address the creation of participatory design fiction, in their case for sustainable energy futures, created by the current users of eco-feedback technology, seemingly aiming at serving the academia as well as future users of sustainable designs [60] or with the vulnerable users of medical technologies, created by the users, aiming at serving both the academia, industry and users [57].

\footnotetext{
${ }^{2}$ Discourses on design fiction are seen as ways of articulating arguments and engaging in design fiction practices, providing ways for orientation to the world, for constituting people and events in it and for reporting of those [59].
}

2.2.2 Dissensus design fiction. This form of design fiction aims, in addition to imagining and exploring (alternative) digital futures, to criticize, deconstruct or provoke, if not even to empower the oppressed and combat the oppressors. Within the former, the status quo is critically scrutinized, challenged, or disturbed by designs created by elitist designers/experts or by the participants. As for the elitist, expert led design fiction, Brown et al. [1] for example, address creation of a Future IKEA Catalogue - with emphasis on equivocality - created in collaboration among researchers, industry and public sector, seemingly serving the academia as well as business/management. Wu et al. [73] go further along the critical trajectory and explore the future of autonomous shipping through design fiction - with emphasis on controversies and ethical issues that is created by researchers in collaboration with industry, serving both the academia and the various stakeholders influenced by autonomous shipping. Søndergaard and Hansen [68] envision, by relying on feminist theories, provocative futures with digital personal assistants. Pschetz et al. [61] utilize design fiction and drama to arouse the civic engagement and deliberation on autonomous distributed energy systems. As for the participant led design fiction with the goal to provoke, criticize and deconstruct, for example Blythe et al. [7] discuss seriously silly design fiction - with emphasis on absurdness - created by researchers considering their later life or by the elderly themselves, aiming at serving the academia and the general public. Within the participant led approach, moreover, Muller and Liao [54] go further along the critical trajectory and explore through participatory design fiction AI ethics, created in collaboration among researchers and users, serving the academia as well as the general public.

\subsection{Children and adolescents using design fiction}

Studies employing design fiction, that is those that orient children to futures that are 5, 10, 50 years ahead, are relatively few, yet fictional inquires and narratives, within the purview of participatory design, have been previously explored with children within CCI (see $[11,28,37,44,53,56])$. These include studies with children with visual impairments employing participatory design explorations of educational spaces that are inclusive [53], with young children (2-7 years) and their caregivers and professionals co-designing embodied learning approaches [56], with children designing fictitious "cartoon personalities" that inspire future children's products [28], and with middle school students at an after school programming club to explore elements how storytelling support the learning how to code [11].

Some studies explicitly utilizing design fiction could also be found. Design fiction has been used to reimagine possible futures from the perspectives of climate change [50], of educational systems for the 21st century [18] of new and emerging technologies [31], and with university students to envision sustainable campuses [32] and discuss the long-term ethical consequences of innovation and technology [75] as well as imagine themselves with communityshared robot in the future [13]. In Maxwell et al.'s [50] project, Telling the Bees, over 80 pupils aged between 9-10 years and from low socio-economic backgrounds in the UK participated either in an intensive week-long exercise or as a regular semester long 


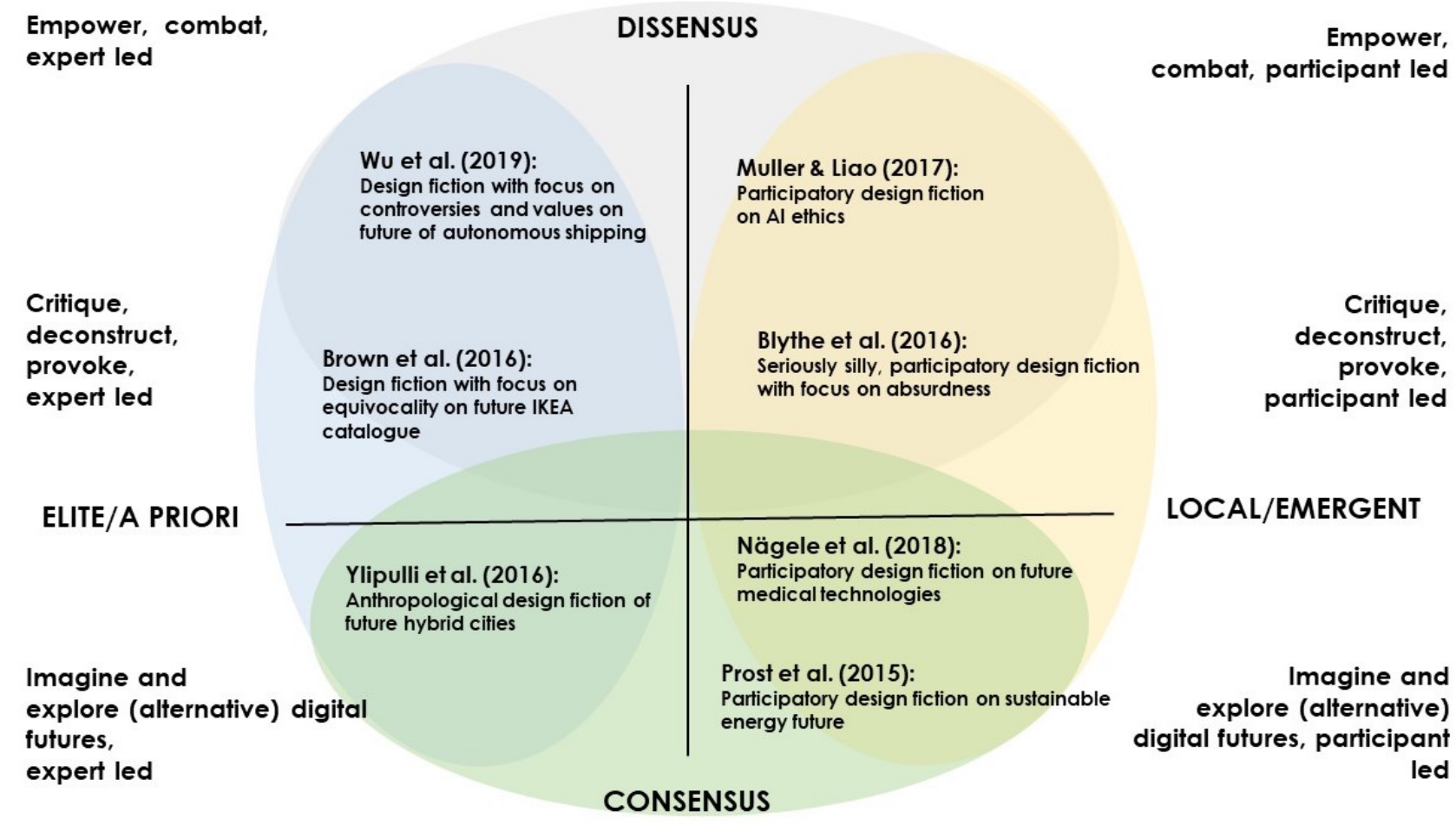

Figure 1: Framework for mapping diversity in design fiction with design fiction example studies

course work. They incorporated three main aspects from the Mantle of the Expert teaching method [33] "which involves learners role-playing as experts in a particular field, is rooted in three pedagogic structures - inquiry learning, drama for learning and expert framing" [50]. In their approach to design fiction, like in our work, pupils role-played as experts, and not as passive learners, to provide imaginative solutions to address the "catastrophic declines in the honeybee population in a near future" [50]. Duggan et al. [18] explored alternative futures for schooling through participatory design fiction with 13-14 year old pupils belonging to disadvantaged communities, in the North West of England. Their school was part of the "Building Schools for the Future vision of future-oriented teaching and learning" and had open learning spaces instead of closed classrooms, a focus on independent and collaborative project work, and students were supported with "one-to-one digital technology", yet in practice, "open learning spaces being retrofitted with soundproof walls to create traditional classroom-style teaching spaces". Researchers explored this mismatch between vision and practice, through world-building, that is detailed design fiction narratives and stories. Hauser et al. [32] made a fake university YouTube channel to share their series of design fiction short films, to "catalyze reactions and blur limits between what is invented and what is real, leading to more reflection on current and future practices surrounding tackled issues" [32]. Researchers have also employed design fiction to imagine future technologies for children, such as Buruk et al. [12], who explore the age of transhumanism [10] in the year 2077 when humans have enhanced augmented sensory and cognitive capabilities. Through their fictional abstracts, the authors raise interesting questions and debates on ethical, socio-political, and economic conditions that arise in the age of transhumanism, and the potential problems and opportunities that are created. Thus, both consensus and dissensus flavors of design fiction have been employed in previous work on children and technology.

However, our literature review did not uncover examples of strongly empowerment-oriented design fictions with children: such studies that would question the status quo as well as take action with design and technology to combat the oppressors. Yet, children are a growing user group who should be invited to envision and critically explore our digital futures. So far, very few studies have explored children's empowerment through participatory design approaches with regard to their technology design and use, encouraging children to explore and critically reflect on the implications of technology to their own future lives [17, 37, 42-44]. Among those, DiPaola et al. [17] explore the ethical implications of technology with middle school children to critically reflect on socio-technical motivations behind such technology, with the goal to transform children "into critical users and ethical designers of technology". This study aims to contribute to this body of research and address the current gap in children's exploration, design, and critical reflections of future technologies in their lives.

\section{RESEARCH DESIGN}

This research is a result of a longitudinal interest in and support for the empowerment and genuine participation of children. Several research projects have been conducted in collaboration with local schools, exploring participatory design and making with children 
and their teachers. In the project involved in this study, we conducted critical design fiction with three different local elementary schools to address bullying that children face in their everyday life. The project followed the Ethics guidelines and criteria of the Finnish National Agency for Research Integrity. Informed consent was asked both from the guardians and study participants. The participating schools involved two classes of sixth graders and one second grade class. See details of the participating classes in Table 1. All the children in the classes participated the activities as part of their schoolwork, but the research data was collected only from those who (and whose guardians) gave informed consent.

\subsection{Design fiction process}

All projects followed somewhat similar critical design and making process consisting of 1) Preparative phase, 2) Design Fiction phase and 3) Closing phase (See Figure 2.)

Preparative phase. The actual project in schools started by sessions sensitizing with the topic. The first part concerned sensitizing with technology and its use in children's lives including tasks such as filling in a technology friendship book - a booklet with several tasks elaborating the child's relationship with technology - and conducting an interview as homework with a parent or other close adult. Next, the topic of bullying was introduced to the participants and elaborated through different tasks such as creating persona descriptions for a bully, bullying victim, and bystander and by writing or drawing scenario descriptions of imagined bullying situations. The final task was writing a letter or email for an imagined bully or a person being bullied.

Design fiction phase. Thereafter, we started to envision alternative futures through several design fiction related sessions including ideation, designing and prototyping, and theater of the oppressed inspired drama performances. From now on the children worked in groups of 3-5. The groups were formed by the teachers prior to the sessions and the groups remained the same throughout the whole project. The ideation process started with a short introduction to design fiction in a form of two sets of videos. The aim of the videos was to orient the participants towards the future, inspire and awake their imagination, and motivate them to consider solutions involving technologies that might not exist yet. The first video introduced the concept of design fiction and the second concentrated on envisioning technology-mediated solutions for bullying. More information about the videos, with an online link, is offered in Section 3.2. For getting started with ideation, we used a therapy inspired Miracle method [49], as a guideline for focus group discussions. The idea was to imagine a world after a miracle. In this case, the miracle was disappearance of bullying and harassing. This method helped to understand how bullying pictures now in children's lives and how the life would be different without it. Before the actual miracle method session, the pupils had practiced the method with the teacher already in advance through a similar miracle method task but with a different topic. The actual ideation started through toy inspired brainstorming sessions. The idea was to first ideate a gadget for creating a bullying-free school and society individually, and for creating better, friendlier, and safer atmosphere for all. A selection of small objects and toys was used as inspirational material. Each pupil picked 1-2 objects and invented magical/technical features for them. After ideating for a while individually, groups of 3-5 children analyzed each of the ideas and combined good features into one shared idea. After coming up with the idea, the groups started to create scenarios or storyboards of bullying events where the ideated gadget would play a role. While coming up with the storyline, pupils also created new persona descriptions of the characters in the story.

Next, we started to analyze the technology concepts critically. First, the groups drew the best- and worst-case scenarios representing the world where the situation was successfully solved with the invented gadget, and a dystopic situation where everything had failed, and the technology had not brought a solution to the problem. In addition, we had a class discussion on the underlying assumptions related to the groups' ideas. The themes of discussion were as follows: Are the users active or passive? Does the technology control or increase empathy? Is bullying a problem of an individual or the whole community? Is the idea problem or solution focused? Finally, we conducted focus group discussion with each of the groups and discussed the underlying assumptions and values of each design idea through ladder interview technique trying to explicate the subconscious motives and underlying values behind the designs.

After ideation, the children continued by designing and prototyping the ideated gadgets. First, a prototype was made using various craft materials such as pipe cleaners, cardboard, craft eyes, hot glue, stickers, ice cream sticks, Styrofoam balls and cones, soft toys. Afterwards, the groups added interactivity to their prototypes using programmable Lego bricks, conductive threads and LilyPad LEDs, Codebug, or Makey Makey.

Finally, we incorporated the theater of the oppressed [7] inspired drama practices in the design fiction process. Drama rehearsals were integrated into the ideation sessions early on for warming-up the children for the drama. In addition, the plots for the skits were prepared already during the scenario writing and children also shared the roles acting in the scenes. During the next sessions, the groups trained acting, first by getting into the role through understanding the feelings of their characters, and then rehearsing the scenes in their groups. Both a scene without the gadget and a scene with the gadget was practiced. Finally, the scenes were presented for an audience, consisting of children and their teachers from other classes from the same school. The presentations were held twice for different audience. The audience (spect-actors) were prepared by presenting what this project was all about and showing them the design fiction videos. After the scene without the gadget, the audience had an opportunity to ask questions from the characters either by picking a question from a pre-shared list or by coming up one by themselves. The idea was to engage the audience in the scenes. A facilitator moderated the sessions, asked the presenters to present their characters before the scenes, encouraged the audience to ask questions from each of the characters in between the skits and finally closed the event.

Closing phase. The last session included short presentations of the prototypes in groups in front of the class and giving constructive feedback for others' prototypes using Post it -notes. After the final session, each child was asked to reflect on their experiences during the project in individual end-interviews. After finishing the project with the pupils, we conducted interviews with the teachers. 


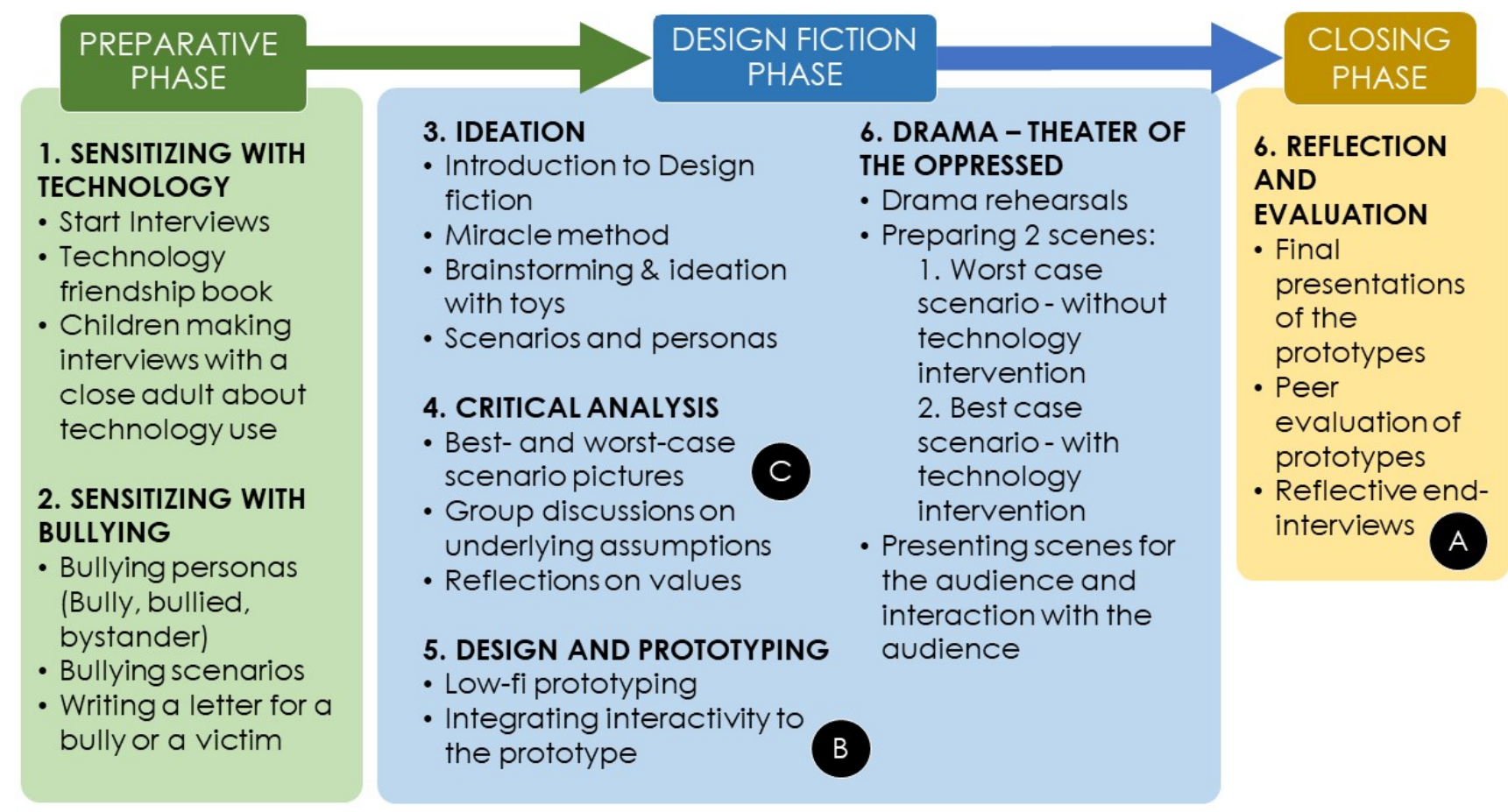

Figure 2: General design and making process including 1) preparative phase concentrating on sensitizing with the topic, 2) design fiction phase including ideation, design and prototyping, and theater of the oppressed and 3) a closing session. Letters $A, B$ and $C$ identify the phase which was reached during the project with each school.

Table 1: Details of the participating classes

\begin{tabular}{cccccl}
\hline School & Grade & N of pupils with consent / N of all pupils & Age of pupils & Gender of pupils & Project conducted until \\
\hline A & 6 & $19 / 22$ & $11-12$ & 8 girls / 11 boys & Entire project \\
B & 2 & $25 / 25$ & $7-9$ & 12 girls / 13 boys & Prototyping phase \\
C & 6 & $23 / 24$ & $11-12$ & 14 girls / 10 boys & Critical analysis phase \\
\hline
\end{tabular}

In the schools, there were some small modifications in the process due to children's different developmental levels and time management issues as we got to work with children in each school different amounts of time per week. For instance, in school B we used several sessions for prototyping, while in school A only one session was used for low-fi prototyping and one was dedicated to adding interactivity to the prototypes. In addition, due to the worsening COVID-19 pandemic in the area and tightening restrictions, we were able to finish the entire project only in school A. With school $\mathrm{B}$, we reached the prototyping phase and with school $\mathrm{C}$ the critical analysis phase (see Figure 2). Thus, the analysis concerning the drama part will concentrate on the experiences of the pupils in school A. The work with school A lasted altogether nine weeks during the fall 2020 and included ten 90-minute sessions with researchers, work with the teacher and some individual homework. The materials and videos used in the project will be made available at the project website (http://interact.oulu.fi/mad).

\subsection{The design fiction videos}

We carefully crafted videos for introducing design fiction for the children $^{3}$. In the sensitizing to bullying video, children are presented several current technology-mediated solutions for preventing, addressing, and reducing bullying. This includes adult interventions for reporting an incident or intervening during an incident, online webpages or a mobile application that has information on reporting bullying, chatbots that provide therapies for all for improved mental health and wellbeing, or even a robot caretaker in the school playgrounds that monitors interactions and mediates when a conflict seems to arise. This leads to a more provocative example where robots or other technology devices watch over students in the school, like big brother, to analyze emotional signals and well-being and stop incidents of bullying before they even occur. From this, the video narrator urges the audience to contemplate on

\footnotetext{
${ }^{3}$ The videos, in English and Finnish, are available at this link: https://drive.google.com/ drive/folders/1EtPeiWZ-drj-Y5e94EGzDWul6wMHGge4?usp=sharing
} 
who is a bully and why does anyone bully now. Why would they bully in the future? And to consider what forms bullying might take on in the future and the role of technology. The video ends on a positive note, imploring the audience to come together to think of solutions to a happy school. The videos were designed to explain and describe the concept of design fiction to those not familiar with the concept, such as young children, and inspire the audience to consider the type of technologies there can be or should be in the future. There are two videos - the first one introduces design fiction and the second one is on bullying at schools with examples of different technologies that could provide solutions to prevent, address, or reduce bullying at schools.

The first video has three parts. In the first part of the video, fiction is introduced as something that we imagine, which is make-believe, that can or may happen in the future. At the beginning of the videos more typical examples are provided to build on familiarity - like flying cars or time travel, or superheroes and cyborgs living among us, and towards the end more unfamiliar and provocative ones. Then a connection is made to science fiction movies, mentioning superheroes and supervillains, to expand on the concept, and mentioning magic and time travel as well. In this way, diverse examples from familiar experiences or ideas are presented. Further, questions on the future of classrooms, specific to the context of our work, are asked to steer the thought process towards children's everyday experiences at school - asking "How will you learn in the future?" or "How will you write or communicate in the future?". The audience is then invited to imagine and make-believe different kinds of schools, classrooms, teachers, and even friends in the future.

In the second part of the video, ways to consider the future are presented in a relatable style to think about 10 years, 50 years, or even a hundred years from now. For instance, the future is described as 10-15 years from now when the children graduate from school and start studying at the university. The near future as 20-25 years from now, when they might start their first job and asking them to consider what it might be and where they might work - on Mars? And then far future as 50 years from now, when they or their friends might have grandchildren and asking them to consider how those grandchildren learn new skills and knowledge at their school in the future. A far far future is described as 100 years from now when their grandchildren have children OR when their grandchildren have grandchildren. In this second part of the video that describes ways to think about the future the voice over or narrator is robotic - to sound like someone or something from the future. In the last part of this video, design fiction is summarized, and the audience is asked to open their minds and think about the impossible - to "Think, Imagine, Draw, Write", as "The future is here".

\subsection{Ethical concerns}

As the topic of our project, bullying, is an issue that can cause lifelong psychological trauma, we had to be extremely sensitive in handling this topic with the children in delicate developmental stage. For this reason, the project with each school started with interviewing the teacher. The teacher interviews concerned for instance technology use at school, bullying in the class and what kind of practices schools have for confronting bullying. The classes did not have serious problems with bullying and the schools had established means for addressing it in case it appeared. We wanted to ensure no severe bullying was occurring within the classes involved in the project. We did not want to conduct our study with a class with acute, severe bullying as we were aware that our study might trigger troubling feelings and memories. The teachers were consulted prior all activities to ensure they were suitable for the classes. Representatives from the schools were present in the project activities. We also asked the teachers to form the teams for the group work in advance. The teachers were able to group the pupils into working teams in which the pupils' individual strengths complemented each other and discrimination or bullying was not likely to happen.

During the project, we acknowledged that the facilitators had to adopt a very responsible and ethical stance towards interaction with children. We were aware of the power play within the class and tried to ensure equal participation and avoid favoring more talkative and loud-voiced children at the expense of others. This was especially highlighted while interacting with children in smaller groups such as in group interviews. However, children were not forced to share ideas or thoughts in any stage. In the preparation phase, for preventing children from sharing troubling or personal information, we highlighted that each produced outcome should not be based on trues stories, but they should be fully imaginary, especially the persona descriptions. During the miracle method interviews, we asked the children to imagine the world without bullying. This exercise reflected the existing pain points but did not describe a single bullying event but rather typical moments when unwanted behaviour emerges. During the drama phase, the pupils had freedom to choose a role they were comfortable playing and a few times it was observed that the children changed their roles during the drama preparation because they did not feel comfortable in the role they chose to play first. Overall, we acknowledge that bullying is a delicate matter with school children. Yet, we think that it is very important to address it. As the teacher in school A said: "It is always important to talk about bullying, even when it is not an acute problem in the class."

\subsection{Data collection and analysis}

The data included in this study contains teacher interview transcriptions, pictures taken throughout the project in each school, field notes from each session, interview and focus group transcriptions, videos recordings of the dramas and all the material children produced during the project such as scenarios and personas, letters, reflective diaries and the prototypes. In this paper, the analysis focused on interview transcriptions from school A, scenario descriptions, concept pictures and prototype pictures from all of the schools and the pictures from the drama practices and videos from the theater of the oppressed event from school A. In the analysis, we examined both the process and the outcomes of our design fiction work with children. The data analysis proceeded the following way. As for the process, all pupil interviews were first transcribed, after which the quotations related to the overall process from the end interviews were collected and categorized in a data-driven manner. In addition to inquiring their overall experiences, we also focused on evidence on children's empowerment, considering empowerment of children both in motivational and relational sense (see [36]); whether the experience was motivating and meaningful to children, allowing them to have a choice and impact as well as to build their competence and whether the experience allowed them to have increased power in issues concerning 
their life. As for the outcomes, the concept descriptions were condensed from children's writings, drawings and verbal descriptions and scene descriptions were created from the video recordings. The prototypes, their descriptions and the scenarios were analyzed for focusing on their underlying assumptions related to human beings and technology (inspired by [41]) as well as on how criticality and empowerment picture in them (see Section 2 and [36]).

\section{DESIGN FICTION IN ACTION}

\subsection{Design fiction through children's prototypes and concepts}

In each school, the children ideated digital means and tools for the prevention of bullying. A variety of ideas emerged. Those are presented in the following Tables 2, 3, 4, 5 and Figures 3, 4, 5. In school A, the groups managed to finalize the project and conduct the theater of the oppressed event, while in schools B and C the child groups managed to produce their group ideas that have not yet been made into prototypes. After prototyping some extra features or functionalities that have not come up yet will likely appear.

\subsection{Design fiction through theater of the oppressed}

In school A, the children presented their prototypes and scenarios through the theater of the oppressed event. The scenes presented provocative situations involving rough events of physical and verbal bullying. Children created the scenarios and personas in the ideation phase, and through the theater of the oppressed preparations the characters and scenes were further developed. All the groups presented scenes with technology intervention, where technology helped to stop the bullying and a scene where technology did not play a role, and nothing interrupted the bullying. This set up highlighted the role of the digital tools in the storyline and thus, the invented technology was seen as a tool for transforming the world into a better place in the scene. The scenarios and scenes related to each prototype of school A are presented in Table 4.

Before acting the scenes for the audience, different preparative phases were conducted. One was to come up with feelings for the characters to deepen the understanding about each role and empathy towards the characters. This was done together in groups so that all members knew what others were thinking and feeling. Feelings were strengthened in the drama session warm up where children expressed feelings with their faces and bodies e.g., saying hello to each other with different feelings. During the theater of the oppressed event, the audience, consisting of children and their teachers from other classes, participated in the process through the opportunity to ask questions from each of the characters in the scenes. Most of the questions concerned the behaviour of the characters in the scenes. While the questions for the bully concerned questioning the bullies' motives, (why the bully bullies and how she/he feels while doing it), the questions for the victim reflected wishes for the victim to take a more active role and to stand up for defending him/herself. For bystanders, the audience was questioning his/her passive role. It was clear that the scenes did not only affect the presenters, but also the audience began to wonder why something happened in the scene and felt empathy for different characters.

\subsection{Children's design fiction experiences}

Children's (school A) overall experiences of the design fiction process were positive, indicating that the design fiction process was empowering in motivational sense: it was a meaningful process (see [36]). They indicated in the interviews that mostly all activities were pleasant if not fun and enjoyable. Mostly enjoyed parts of the process were making and presenting the drama and making the prototype - they involved groupwork and crafts. Three pupils mentioned the ideation of personas and scenarios as their favorite. Some children thought technology was fun, some enjoyed ideating and the technology diary tasks, and many thought that working with the scenarios, the prototype and the drama in their groups were the most fun. Ideation, making and presenting the drama and building the prototype were also clearly the most challenging tasks. As the more difficult tasks were also the most enjoyable ones, perhaps challenge was a positive factor. For example, the miracle method was said to be difficult by many; however, all children agreed that it was useful, and the children got good ideas from there. On the negative side, the background assumptions, reflections and the technology friendship book were said to be boring by some pupils and many didn't remember those tasks anymore at the end interviews. Few students felt like there was not enough time to build the prototype or ideate the scenario. Only one pupil said they didn't enjoy performing the drama. Apart from those answers, the pupils couldn't think of anything they didn't particularly like in the process. Working in groups was a big part of the project and most felt like they found their place in the group and that the group was working well together. This feeling was meaningful to the overall positive experience of the process. Some pupils, however, maintained that their group impacted the process negatively for them, even though also they enjoyed other things about it.

The theater of the oppressed part received mostly positive comments from the children although many children reported on being nervous during it. In the interviews, the children reported on how they were able to relate to the feelings of the characters and they felt empathy towards those bullied. The children experienced this as an empowering experience both in motivational and relational sense (see [36]): they gained valuable skills and abilities through which to take action and have an impact in the world. They maintained that this experience enabled them to see the consequences of bullying and to act on it, if encountered. The children considered that they themselves as well as the audience had learned something valuable during the experience. Some children considered the theater of the oppressed explicitly as an empowering experience.

Considering what the children had gained or learned during the overall design fiction process, empowerment emerged again in the sense of perceived meaningfulness as well as the sense of having a say and an impact (see [36]). The children were asked if they would like to ideate these types of technological solutions to problems like bullying in the future and many answered "yes". The interest to dig deeper and keep ideating indicates that the process was encouraging and thought provoking for the pupils. This indication is strengthened through the many types of things 
Table 2: Prototypes and prototype concepts of school A

\begin{tabular}{|c|c|}
\hline Group & Prototype description \\
\hline $\begin{array}{l}\text { Group } 1 \\
\text { Electric shock robot }\end{array}$ & $\begin{array}{l}\text { A stuffed toy that detects bullying. It uses a teleport to transport from one place to another and } \\
\text { punishes the bully with an electric shock. It also films all the bullying situations for preventing } \\
\text { unjust accusations. The prototype includes programmable Lego bricks making it. }\end{array}$ \\
\hline Group 2 & A size-changing police car, that can be called via an app. The bully can be brought into the \\
\hline Futuristic anti-bullying & car and the car itself comforts the ones being bullied. The group made an app that included \\
\hline Police car & $\begin{array}{l}\text { the information about the location of the car and included Codebug in their prototype, which } \\
\text { provided the viewers with different kinds of messages such as "The police has been called". }\end{array}$ \\
\hline Group 3 & An invisible pig robot, that recognizes bullies and all the sad people near it. The pig-robot \\
\hline $\begin{array}{l}\text { Music playing comfort- } \\
\text { ing robot pig }\end{array}$ & $\begin{array}{l}\text { plays music, so that the one being bullied cant hear the mean words, said by the bullies. The } \\
\text { prototype included programmable Lego bricks that made it move. }\end{array}$ \\
\hline Group 4 & A group of robots consisting of a monkey, crocodile, dog and Santa. The team can be called to \\
\hline $\begin{array}{l}\text { A punishing and re- } \\
\text { warding robot team }\end{array}$ & $\begin{array}{l}\text { where bullying occurs. The team talks with the bully and if needed, it punishes the bully. The } \\
\text { possible punishments are for example cleaning the school after hours. The team of robots also } \\
\text { rewards the bullies when they stop the mean behavior. The group included in their prototype } \\
\text { LilyPad led lights. }\end{array}$ \\
\hline Group 5 & A prototype is a combination of a hippo and a snail, that gives everyone who enters the \\
\hline Empathy stamp robot & $\begin{array}{l}\text { school premises a heart stamp. The stamp deletes all negative thoughts and creates a happy } \\
\text { environment, so that no bullying occurs at the school. This group also included LilyPad LEDs } \\
\text { in their prototype and had led lights inside their stuffed animal. }\end{array}$ \\
\hline
\end{tabular}

Table 3: Prototypes and prototype concepts of school B

\begin{tabular}{|c|c|}
\hline Group & Prototype description \\
\hline $\begin{array}{l}\text { Group } 1 \\
\text { Plane-Car vehicle that } \\
\text { transforms bullies into } \\
\text { friends using hearts } \\
\text { emerging from ink balls }\end{array}$ & $\begin{array}{l}\text { An airplane and car are combined to cruise over the places where bullying could occur and to } \\
\text { monitor the situation in the groups using a camera placed at the bottom of the vehicle which } \\
\text { sees the bullies, as it's flying. Additionally, a teacher or one of the team members, that are also } \\
\text { the crew members in the vehicle, can call the vehicle to come to the bullying scene. The vehicle } \\
\text { has ink balls that have hearts and hearts have the power to turn the bullies into friends. The } \\
\text { group also toyed with the providing one of the group members with super speed and stamps } \\
\text { that it uses to make the bullies into friends. }\end{array}$ \\
\hline $\begin{array}{l}\text { Group } 2 \\
\text { Robot that converts bul- } \\
\text { lies into friends and can } \\
\text { be called with mobile } \\
\text { app }\end{array}$ & $\begin{array}{l}\text { This group developed the idea of a button that connects with a mobile application, which calls } \\
\text { a robot to come and help when bullying is detected. The robot helps by talking to the bully and } \\
\text { asking them why they are bullying, so the bully gets distracted. Through the talking, the bully } \\
\text { is converted into a friend. The person being bullied can call for help by using the app. }\end{array}$ \\
\hline Group 3 & A superhero called super girl who can also transform into a super truck, similar to transformers. \\
\hline $\begin{array}{l}\text { Mind controlling super } \\
\text { girl-truck robot }\end{array}$ & $\begin{array}{l}\text { The super girl / super truck has superpowers that include some form of mind control through } \\
\text { their gadgets - a fidget spinner and fire blades. The super girl transforms into a car/truck so } \\
\text { she can go to the place where the bullying is happening. Bystanders call for her to come and } \\
\text { help. The bully is stopped through mind control and using the different gadgets. }\end{array}$ \\
\hline $\begin{array}{l}\text { Group } 4 \\
\text { Empathy raising roller } \\
\text { skates }\end{array}$ & $\begin{array}{l}\text { Autopiloted roller skates, that have many bullying preventing features. The skates have bouncy } \\
\text { balls that convert the bully into a nice person. In addition, there are heart bubbles that come out } \\
\text { of the skates when a button is pressed and those go to the bully and stop them from bullying. } \\
\text { There is also some bullying sensing mechanism so that the skates go to the right place. Lastly, } \\
\text { there is a button on the skates that releases perfume that goes to the bully's nose and they stop } \\
\text { bullying. }\end{array}$ \\
\hline $\begin{array}{l}\text { Group } 5 \\
\text { Bullies detecting and } \\
\text { capturing pig robot }\end{array}$ & $\begin{array}{l}\text { A bouncy pig that has a net to catch bullies with and if you are caught you need to give some } \\
\text { money to the pig in order to be freed from the net. The interaction with the pig, through the } \\
\text { pig tapping on the shoulder of the bully, turns the bully into a good person. The pig knows } \\
\text { where the bullying is happening, or it has a lie detector, or a bystander can call it. }\end{array}$ \\
\hline
\end{tabular}



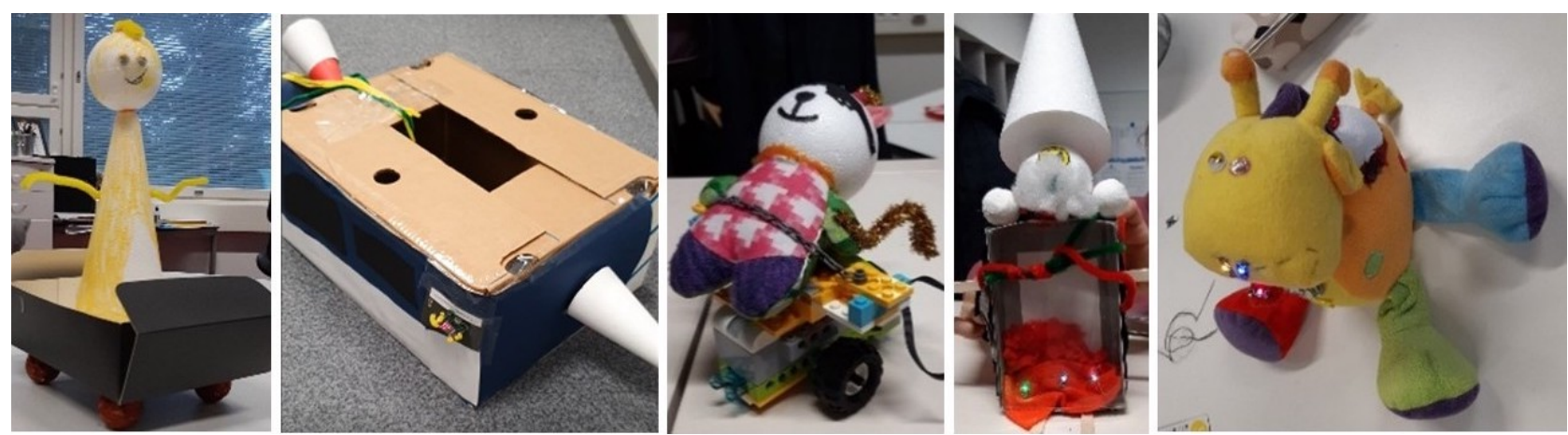

Figure 3: Children's prototypes in school A. From the left: Electric shock robot, anti-bullying police car, comforting music robot, robot team, empathy stamp robot.
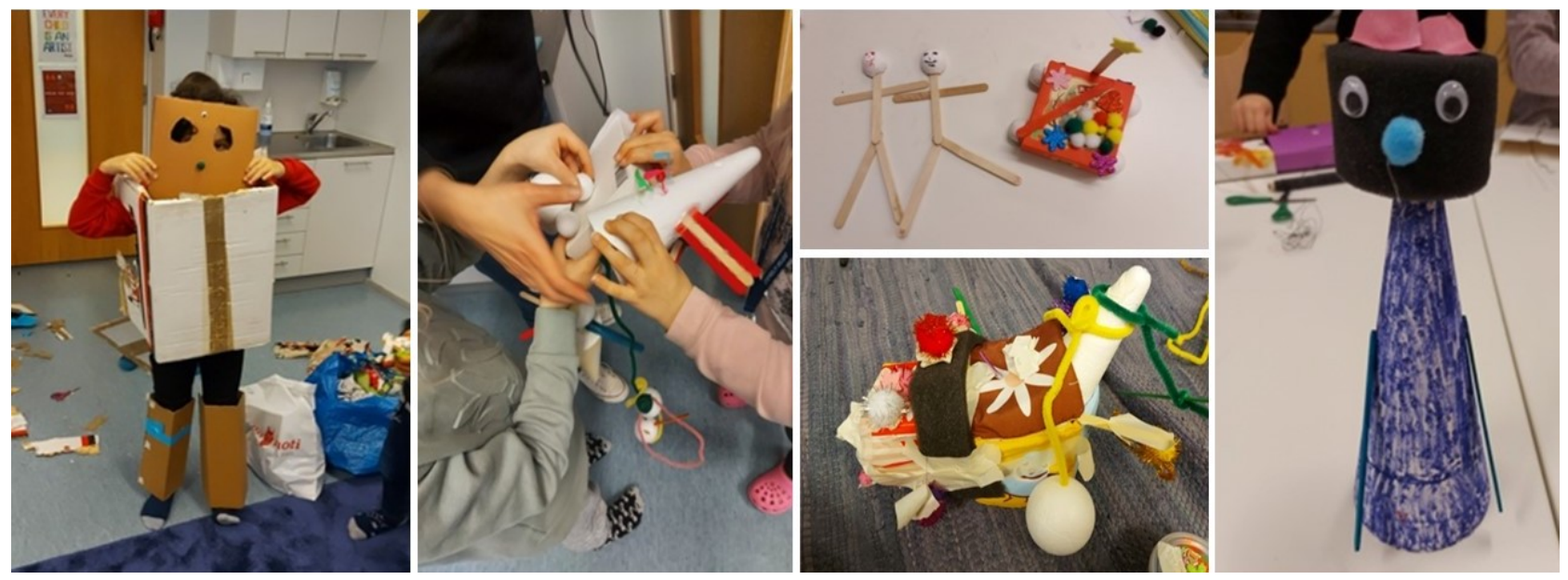

Figure 4: Children's prototypes in school B. From the left: Plane-Car vehicle, Robot that converts bullies into friends, Mindcontrolling super girl-truck robot, Empathy raising roller skates (below), Bullies detecting and capturing pig robot.
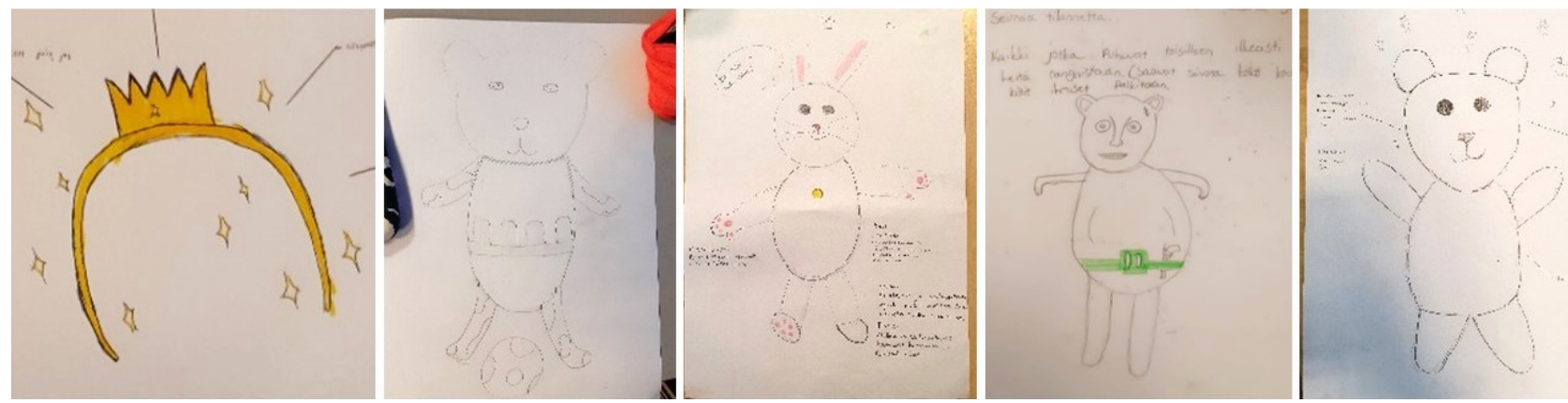

Figure 5: The childrens concept drawings in school C. From left: Empathy increasing headband, comforting joke telling teddy robot, bullying detecting bunny robot, a tiger robot with monitoring camera eyes, bullying measuring teddy robot.

the pupils saw they had learned during the process. Those included how to play with and handle different forms of technology, how to identify bullying and act against it, what the consequences of bullying are if the problem is not addressed, how other people think and feel about bullying and how technology can be used to help with different issues such as bullying. Also, most pupils implied that their thoughts about bullying and technology had changed after the project. 
Table 4: Prototypes and prototype concepts of school C

\begin{tabular}{|c|c|}
\hline Group & Prototype description \\
\hline Group 1 & eadband which turns every bully nice an \\
\hline $\begin{array}{l}\text { Magic head band that } \\
\text { increases empathy }\end{array}$ & $\begin{array}{l}\text { It detects bullying, racism and other discrimination that occurs near it and creates a positive } \\
\text { atmosphere. }\end{array}$ \\
\hline Group 2 & A stuffed toy robot. The robot senses when bullying occurs and makes it stop. It comforts and \\
\hline $\begin{array}{l}\text { Comforting joke telling } \\
\text { teddy shaped robot }\end{array}$ & $\begin{array}{l}\text { talks to everyone if they need a company, tells jokes and makes people laugh. The robot sends } \\
\text { a message to the teacher if bullying occurs. }\end{array}$ \\
\hline Group 3 & Bunny is a robot that flies to the bullied if he/she needs help. It has a golden armour and its \\
\hline $\begin{array}{l}\text { Bullying detecting } \\
\text { bunny robot }\end{array}$ & $\begin{array}{l}\text { always happy. The robot detects bullying and tells the teacher by sending a message. The bunny } \\
\text { has a slogan which can be translated to "stop the fighting by using bunny". }\end{array}$ \\
\hline Group 4 & A tiger warrior is a stuffed toy robot that is used to monitor the school. The robots eyes are \\
\hline $\begin{array}{l}\text { A tiger robot with mon- } \\
\text { itoring camera eyes }\end{array}$ & $\begin{array}{l}\text { camera lenses and it sends direct video to a "man behind the computer". If someone says mean } \\
\text { things, they will be punished, for example they need to clean the entire school. The robot also } \\
\text { rewards good behaviour. }\end{array}$ \\
\hline Group 5 & Teddy bear robot which eyes change color, depending on how serious bullying it detects. If \\
\hline $\begin{array}{l}\text { Bullying measuring } \\
\text { teddy robot }\end{array}$ & needed, little teddies come out of the robot's nose, and they help the one being bullied. \\
\hline
\end{tabular}

Table 5: The scene descriptions with technology intervention during the theater of the oppressed in school A.

\begin{tabular}{|c|c|}
\hline Group & Scenario / Scene description with technology intervention \\
\hline $\begin{array}{l}\text { Group } 1 \\
\text { Electric shock robot }\end{array}$ & $\begin{array}{l}\text { A child (victim) is walking along a street. The bully enters the scene and starts kicking the } \\
\text { victim. Suddenly the robot teleports to the scene and gives an electric shock to the bully. } \\
\text { Bullying stops and the bully leaves the scene. }\end{array}$ \\
\hline Group 2 & A child (victim) enters to the scene happily. The bully starts to call the victim stupid, pushes \\
\hline Futuristic anti-bullying & the victim who then falls. The bully continues kicking the victim while the victim is lying on \\
\hline Police car & $\begin{array}{l}\text { the ground. A passer-by uses a portable device to call the police car. The police car enters the } \\
\text { scene, helps the victim, and takes the bully away. }\end{array}$ \\
\hline Group 3 & A child (victim) is dancing in the scene, then the bully starts to make fun of the child. A passer- \\
\hline $\begin{array}{l}\text { Music playing comfort- } \\
\text { ing robot pig }\end{array}$ & $\begin{array}{l}\text { by interferes and the pig robot enters the scene. The pig robot starts to play music around the } \\
\text { victim, who doesn't hear the bullies anymore. Bullies stop making fun of the victim, as the } \\
\text { victim doesn't react anymore. }\end{array}$ \\
\hline Group 4 & A child (victim) sends a message accidentally to a bully, who then hits the victim because of it. \\
\hline $\begin{array}{l}\text { A punishing and re- } \\
\text { warding robot team }\end{array}$ & $\begin{array}{l}\text { Another child tries to video record the event and bully hits him, too, and he drops his phone. A } \\
\text { passer-by calls the team of robots to the scene. The robot team of robots punishes the bully by } \\
\text { making the bully clean the school for a week. }\end{array}$ \\
\hline Group 5 & A child (victim) is playing with a mobile phone. Another child (bully) asks if she can play with \\
\hline Empathy stamp robot & $\begin{array}{l}\text { it too, but the victim says no. The bully then breaks the victim's phone and hits the victim. A } \\
\text { passer-by enters the scene and bully hits her too. The robot enters the scene and gives a stamp } \\
\text { to everyone making them become friends and no bullying happens anymore. }\end{array}$ \\
\hline
\end{tabular}

\section{DISCUSSION AND IMPLICATIONS}

This section discusses the implications of our results for HCI research and design fiction practice.

\subsection{Participatory, empowering design fiction with children}

Our research explored how to encourage critical engagement of children to address the problem of bullying through design and technology. As an answer, we propose participatory and empowering design fiction in collaboration with children. Our study shows an example how it can be accomplished with children. Next, we discuss the process and outcomes of our participatory, empowering design fiction in more detail, scrutinizing in which sense we consider it to be participatory and empowering.

As for the process, we maintain that the critical agenda strongly pictures in the process: there is "an intention to change the status quo, overcome injustice and alienation, and promote emancipation" [67].The children managed to envision a fascinating set of digital means and tools to tackle the widespread, troublesome societal problem of bullying that is intimately intertwined with injustice and alienation in our society. In addition, they also managed to 
invite teachers and other children in their school to consider the problem and potential solutions for tackling it. Hence, as for participation and empowerment, the children adopted the position of central actors, protagonists [46] in the process, taking action and responsibility. The children engaged in the theater of the oppressed performances, which have been particularly devised to empower people, both the actors and the spect-actors, to liberate themselves from oppression and false consciousness [7]: Boal argues that "Theater is necessarily political, because all the activities of man are political, and theater is one of them" [7] and that theater is a weapon, an efficient one, that can be used for the liberation of the oppressed. In line with this, we maintain that we invited children to utilize design fiction including theater as a weapon to liberate us all from the problem of bullying. Our analysis shows we managed to offer empowering experiences for the children involved, and in different senses including the motivational and the relational sense (see also [36]).

As for the outcomes of the design fiction, we see interesting distinctions in the children's designs (see Table 6). Inspired by [41], we categorize the children's designs along a continuum, where one end represents Theory $\mathrm{X}$ assumptions about the human being: people as seen as lazy and unmotivated to tackle the problem of bullying; hence, they need to be monitored, controlled, and pushed to achieve a desired outcome and the focus is on problem identification and associated action taking. The other end relies on Theory $\mathrm{Y}$ assumptions: people are seen as active and motivated, taking ownership and responsibility for bullying, their action taking entailing a collective approach with a focus on strengths and positive futures rather than on the problems of today. Children's designs representing both theories could be identified in our study. We consider all designs as empowering, while the Theory Y oriented designs more strongly so than Theory X oriented ones. Regarding criticality, furthermore, we maintain the children's designs work within the dissensus discourse in the sense of aiming at challenging and disrupting the "dominant set of structurings of knowledge". However, there are differences in how far the children went in their designs in terms of critiquing, deconstructing or provoking: some designs included unexpected, surprising or provocative elements more clearly than others. Moreover, there are differences in far the children went in their designs in terms of empowering the oppressed and combatting the oppressors: again, some designs were more explicit in addressing the power difference and power dynamics among the bullies and those bullied than others.

However, when addressing such a wicked problem as bullying, we cannot expect any easy solutions (see [16]). We know the concrete solutions designed by children are not implementable as such. However, while engaging in the process, empowered to envision and design the better future, these designs become means and tools for participatory mutual learning for all participants involved, for children to learn to express themselves in relation to the troublesome topic but for adults as well to understand children's relationship with such a complex problem. For example, we may consider electric shock as children's real expression of the urgent need for someone to really intervene. As such, this naïve solution expresses how strong relationship children experience with the issue in question and children's stance in regards the imaginary future. In the end, visioning the future, with no restrictions, empowers children to express their inner thoughts and orientation to the topic. Adults, on the other hand, need to take these children's solutions, as naïve as they are, as valued contributions in need for more in-depth, multidisciplinary analysis and further development, yet still continuing in collaboration with all those involved, with the vulnerable ones most importantly.

\subsection{Call for more participatory and empowering design fiction within the dissensus discourse}

Even if we were able to identify interesting, and divergent, examples of design fiction in our mapping of the literature, we regret to say that as regards the use of design fiction to empower the oppressed and/or to combat the oppressors, we did not find a great number of examples from HCI. Even if we see a lot of value in critical design fiction that aims to deconstruct, criticize and question the status quo and the taken for granted assumptions, we also think design fiction should be utilized more directly for the purpose of empowerment of the power weak, marginalized, dominated, oppressed - be that design fiction created by elitist expert designers or by local participants. Even if the empowerment of people is already discussed [60] and the theater of the oppressed is mentioned as a source of inspiration [58], both indicating the engagement with the critical agenda, so far the endeavors have not been too empowering or combatting ones.

We engaged ourselves in the practice of creating design fiction within the dissensus discourse. Our project enables reflecting on what the participant led, empowering design fiction may entail in $\mathrm{HCI}$, who decides on its contents and who defines the futures to be aimed at - even if we acknowledge that our participant group of children makes our work specific in many ways and our results not generalizable to any HCI project. We wish to highlight that in participatory, empowering design fiction with different kinds of participants, many ethical and value laden aspects are involved. What is provocative for one, may not be such for the other. What is oppressing for one, may not be such for the other. In addition, what we consider empowering of the oppressed or combatting the oppressors may not be considered such by the oppressed. Despite these challenges, we are positive about the potential of critical design fiction to transform the world: to "change the status quo, overcome injustice and alienation, and promote emancipation" [67].

We particularly promote participatory and collective approaches, not only for the topic of bullying, but generally for the empowerment of the oppressed. Aligning with the participatory tradition, we advocate viewing people rather as active agents making a change in the world by themselves than as passive objects in interventions defined by the elite. We consider a collective approach as more beneficial than heavily individual focused: as for empowerment, social responsibility and action taking for an entire collective are recommended rather than working on behalf or on the side of an individual only (see also $[36,46])$. The notions of social responsibility and collective approach to empowerment resonate well with the ideas of Boal and Freire [8, 25], who advocate the liberation of the oppressed as well as the oppressors through collaborative endeavors. Therefore, while design fiction combined with persuasive 
Table 6: Underlying assumptions in children's designs

\begin{tabular}{|c|c|c|}
\hline Analytic focus & Underlying assumptions & Children's design fiction in terms of empowerment \\
\hline \multirow{5}{*}{$\begin{array}{l}\text { Assumptions } \\
\text { about the } \\
\text { human being } \\
\text { Assumptions } \\
\text { about the } \\
\text { nature of the } \\
\text { intervention }\end{array}$} & $\begin{array}{l}\text { Humans passive objects of ob- } \\
\text { servation vs. active agents mak- } \\
\text { ing a change }\end{array}$ & $\begin{array}{l}\text { Emphasis on technology for control, surveillance, monitoring and detec- } \\
\text { tion of bullying, but also on technology arousing human empathy and } \\
\text { agency - both emphasize empowerment, but the latter more strongly }\end{array}$ \\
\hline & $\begin{array}{l}\text { Problem-focused vs. solu- } \\
\text { tion/strength focused }\end{array}$ & $\begin{array}{l}\text { Emphasis on bullying detection and associated action taking, but also } \\
\text { on creation of positive atmosphere and transforming of bullies into nice } \\
\text { persons - both emphasize empowerment, but the latter more strongly }\end{array}$ \\
\hline & Individualistic vs. collectivist & $\begin{array}{l}\text { Emphasis on identification and working with bullies and the ones bul- } \\
\text { lied as individuals, but also on engaging children and adults more } \\
\text { broadly to tackle the problem - both emphasize empowerment, but the } \\
\text { latter advocates a stronger form of collective empowerment and social } \\
\text { responsibility }\end{array}$ \\
\hline & $\begin{array}{l}\text { Critiquing, deconstructing or } \\
\text { provoking }\end{array}$ & $\begin{array}{l}\text { All outcomes critical of the current dynamics, while some entail some- } \\
\text { what unexpected or surprising solutions and some even somewhat } \\
\text { provocative ones (e.g. electric shocks) }\end{array}$ \\
\hline & $\begin{array}{l}\text { Empowering the oppressed, } \\
\text { combatting the oppressors }\end{array}$ & $\begin{array}{l}\text { All outcomes aim at empowering the ones being bullied, while some } \\
\text { suggest combatting the power of bullies in a more explicit way; the } \\
\text { performances inviting also the spect-actors to critical reflection and } \\
\text { action taking }\end{array}$ \\
\hline
\end{tabular}

games, for example, already has great potential to provide opportunities for individuals to experience and engage with challenging topics (see [59]), we consider our participatory critical design fiction approach having great potential for more social and shared engagement, perhaps smoothening the way for personal reflection if not even changing behaviors.

\subsection{Call for design fiction, theater, and therapy}

Inspired by Boal $[8,9]$, we continue by discussing the relationship between design fiction, theater and therapy. Indeed, Boal [8] connects theater and therapy: "Theatre is a therapy into which one enters body and soul, soma and psyche" (pp. 28). The potential of combining participatory and therapy-based approaches has already been discussed in HCI [41], therapy based approaches emphasize collective and solution and strength focused approaches as well as discursive and dialogical interventionist approaches $[47,76]$ that we consider highly valuable for HCI researchers working with challenging and complex topics around empowerment and with marginalized groups or communities. Naturally, HCI researchers cannot and should not act as therapists, but they could follow some valuable principles from therapy-based approaches. We see developments also within other disciplines indicating the potential of theater and therapy in the empowerment of different kinds of marginalized groups or communities. Studies have, for example, explored ethno-theater within narrative therapy for the victims of human trafficking with the goal of making them feel important and empowered [45]. Theater has also been used in [70] with refugees to increase their social and emotional skills and in [72] with disadvantaged young people for strengthening their capabilities to manage their lives. Moreover, there are studies [55, 62] where the capacities of homeless have been strengthened through social theater, offering emancipatory and inclusive experiences for those involved. We see these studies pointing in the same direction as our approach in collaboration with children on the topic of bullying at school: those marginalized, oppressed, dominated or excluded should be invited to collaboratively try to make a change in the world - by the means of design and technology, theater and therapy - for their own empowerment and emancipation as well as for those of a larger collective. They are to be collaboratively invited and encouraged to explore the oppressing conditions of the status quo as well as to take action towards a better future.

\section{CONCLUSION}

We see a lot of potential in design fiction from the perspective of addressing wicked problems and the critical agenda, which is arousing a lot of interest in HCI currently. Through our literature review, we pointed out lack of critical design fiction targeting the empowerment of the power-weak, marginalized, dominated, or oppressed. We explored participatory, empowering design fiction with school children for finding solutions for the serious everyday problem at many school environments - bullying. Through the design fiction process, the children managed to envision a fascinating set of digital means and tools to tackle the problem of bullying at school. We showed that both the process and the outcomes were empowering in certain senses. We recommend participatory and empowering genre of design fiction for projects with children: children should be invited to be the central actors, protagonists in the process of tackling serious societal problems through design and technology. Considering the ever-increasing digitalization of our everyday lives and societies, there is a lot of potential in this type of participatory critical design fiction for the purpose of addressing real societal issues. Along the way, we advocate taking inspiration from design fiction, theater and therapy. 


\section{ACKNOWLEDGMENTS}

This study was funded by Academy of Finland (Grant 324685, Make-a-Difference project). This research is connected to the GenZproject, a strategic profiling project in human sciences at the University of Oulu, supported by the Academy of Finland (Grant 318930) and the University of Oulu.

\section{REFERENCES}

[1] 2016. The IKEA catalogue: Design fiction in academic and industrial collaborations. Proceedings of the International ACM SIGGROUP Conference on Supporting Group Work 13-16-November-2016. https://doi.org/10.1145/2957276.2957298

[2] Mats Alvesson and Stanley Deetz. 2014. Doing Critical Management Research. Do ing Critical Management Research (2014). https://doi.org/10.4135/9781849208918

[3] Alissa N. Antle, Ofir Sadka, Iulian Radu, Boxiao Gong, Victor Cheung, and Uddipana Baishya. 2019. Emototent: Reducing school violence through embodied empathy games. Proceedings of the 18th ACM International Conference on Interaction Design and Children, IDC 2019. https://doi.org/10.1145/3311927.3326596

[4] James Auger. 2013. Speculative design: Crafting the speculation. Digital Creativity 24 (2013). Issue 1. https://doi.org/10.1080/14626268.2013.767276

[5] Eric P.S. Baumer, Mark Blythe, and Theresa Jean Tanenbaum. 2020. Evaluating design fiction: The right tool for the job. DIS 2020 - Proceedings of the 2020 ACM Designing Interactive Systems Conference. https://doi.org/10.1145/3357236. 3395464

[6] Gro Bjerknes and Tone Bratteteig. 1995. User participation and democracy: A discussion of Scandinavian research on system development. Scandinavian fournal of information systems 7 (1995), 1. Issue 1.

[7] Mark Blythe, Kristina Andersen, Rachel Clarke, and Peter Wright. 2016. Anti solutionist strategies: Seriously silly design fiction. Conference on Human Factors in Computing Systems - Proceedings. https://doi.org/10.1145/2858036.2858482

[8] Augusto Boal. 2000. Theater of the Oppressed. Pluto press.

[9] Augusto Boal. 2013. The rainbow of desire: The Boal method of theatre and therapy. Routledge.

[10] Nick Bostrom. 2005. Transhumanist values. Journal of philosophical research 30, Supplement (2005), 3-14.

[11] Quinn Burke and Yasmin B. Kafai. 2010. Programming and storytelling: Opportunities for learning about coding and composition. Proceedings of IDC2010: The 9th International Conference on Interaction Design and Children. https: //doi.org/10.1145/1810543.1810611

[12] Oguz'Oz’ Buruk, Oguzhan Ȯzcan, Gökçe Elif Baykal, Tilbe Göksun, Selçuk Acar Güler Akduman, Mehmet Aydln Baytaş, Ceylan Beşevli, Joe Best, Aykut Coşkun, Hüseyin Ugur Genç, A. Baki Kocaballi, Samuli Laato, Cássia Mota, Konstantinos Papangelis, Marigo Raftopoulos, Richard Ramchurn, Juan Sádaba, Mattia Thibault, Annika Wolff, and Mert Yildiz. 2020. Children in 2077: Designing children's technologies in the age of transhumanism. Conference on Human Factors in Computing Systems - Proceedings. https://doi.org/10.1145/3334480.3381821

[13] Eun Jeong Cheon, Stephen Tsung Han Sher, Šelma Sabanović, and Norman Makoto Su. 2019. I beg to differ: Soft conflicts in collaborative design using design fictions. DIS 2019 - Proceedings of the 2019 ACM Designing Interactive Systems Conference. https://doi.org/10.1145/3322276.3322350

[14] Wai Fong Chua. 1986. Radical developments in accounting thought. Accounting review (1986), 601-632.

[15] Stanley Deetz. 1996. Crossroads-Describing differences in approaches to organization science: Rethinking Burrell and Morgan and their legacy. Organization science 7 (1996), 191-207. Issue 2.

[16] Norman Denzin and Yvonna Lincoln. 2000. Handbook of Qualitative Research. SAGE Publications.

[17] Daniella Dipaola, Blakeley H. Payne, and Cynthia Breazeal. 2020. Decoding design agendas: An ethical design activity for middle school students. Proceedings of the Interaction Design and Children Conference, IDC 2020. https://doi.org/10.1145/ 3392063.3394396

[18] James R. Duggan, Joseph Lindley, and Sarah McNicol. 2017. Near Future School: World building beyond a neoliberal present with participatory design fictions. Futures 94 (2017). https://doi.org/10.1016/j.futures.2017.04.001

[19] Anthony Dunne. 1999. Hertzian Tales. Electronic Products, Aesthetic Experience, and Critical Design. MIT press.

[20] Anthony Dunne and Fiona Raby. 2001. Design Noir: The Secret Life of Electronic Objects. Springer Science '|\&' Business Media.

[21] Anthony Dunne and Fiona Raby. 2013. Speculative everything: Design, fiction, and social dreaming. MIT press. https://doi.org/10.1093/jdh/epv001

[22] Eva Eriksson, Gökçe Elif Baykal, Staffan Björk, and Olof Torgersson. 2019. Using Gameplay design patterns with children in the redesign of a collaborative colocated game. Proceedings of the 18th ACM International Conference on Interaction Design and Children, IDC 2019. https://doi.org/10.1145/3311927.3323155
[23] Laura Forlano and Anijo Mathew. 2014. From Design Fiction to Design Friction: Speculative and Participatory Design of Values-Embedded Urban Technology. fournal of Urban Technology 21 (2014). Issue 4. https://doi.org/10.1080/10630732. 2014.971525

[24] Christopher Frauenberger, Katta Spiel, Laura Scheepmaker, and Irene Posch. 2019. Nurturing constructive disagreement agonistic design with neurodiverse children. Conference on Human Factors in Computing Systems - Proceedings. https://doi.org/10.1145/3290605.3300501

[25] Paulo Freire. 2000. Pedagogy of the oppressed. Continuum.

[26] Lalya Gaye, Atau Tanaka, Ranald Richardson, and Kazuhiro Jo. 2010. Social inclusion through the digital economy Digital creative engagement and youthled innovation. Proceedings of IDC2010: The 9th International Conference on Interaction Design and Children. https://doi.org/10.1145/1810543.1810612

[27] J. Greenbaum and M. Kyng. 1991. Design at Work: Cooperative Design of Computer Systems. Design at Work Cooperative Design of Computer Systems Design at (1991). Issue 1.

[28] Cathy Grundy, Lyn Pemberton, and Richard Morris. 2012. Characters as agents for the co-design process. ACM International Conference Proceeding Series. https: //doi.org/10.1145/2307096.2307120

[29] Lynne Hall, Susan Jones, Ana Paiva, and Ruth Aylett. 2009. FearNot! Providing Children with Strategies to Cope with Bullying. In Proceedings of the 8th International Conference on Interaction Design and Children. Association for Computing Machinery, New York, NY, USA, 276-277. https://doi.org/10.1145/1551788. 1551854

[30] Lynne Hall, Sarah Woods, Kerstin Dautenhahn, and Polly Sobreperez. 2004. Using storyboards to guide virtual world design. Proceedings of the 2004 Conference on Interaction Design and Children: Building a Community, IDC 2004. https: //doi.org/10.1145/1017833.1017853

[31] Alison Hardy. 2019. Using Design Fiction to Teach New and Emerging Technologies in England. Technology and Engineering Teacher 78 (2019). Issue 4.

[32] Sabrina Hauser, Audrey Desjardin, and Ron Wakkary. 2014. SFUture - Envisioning a sustainable university campus in 2065. Proceedings of the Conference on Designing Interactive Systems: Processes, Practices, Methods, and Techniques, DIS. https://doi.org/10.1145/2598784.2602774

[33] Dorothy Heathcote and Gavin M Bolton. 1994. Drama for Learning: Dorothy Heathcote's Mantle of the Expert Approach to Education. Dimensions of Drama Series. ERIC.

[34] Nathan Holbert. 2016. Leveraging cultural values and "ways of knowing" to increase diversity in maker activities. International fournal of Child-Computer Interaction 9-10 (2016). https://doi.org/10.1016/j.ijcci.2016.10.002

[35] J. Iivari. 1991. A paradigmatic analysis of contemporary schools of IS development. European Journal of Information Systems 1 (1991). Issue 4. https://doi.org/10. 1057/ejis.1991.47

[36] Netta Iivari. 2020. Empowering children to make and shape our digital futures from adults creating technologies to children transforming cultures. International fournal of Information and Learning Technology 37 (2020). Issue 5. https://doi. org/10.1108/IJILT-03-2020-0023

[37] Netta Iivari and Marianne Kinnula. 2018. Empowering Children through Design and Making: Towards Protagonist Role Adoption. In Proceedings of the 15th Participatory Design Conference: Full Papers - Volume 1 (PDC '18). Association for Computing Machinery, New York, NY, USA, Article 16, 12 pages. https: //doi.org/10.1145/3210586.3210600

[38] Netta Iivari, Marianne Kinnula, and Leena Kuure. 2015. With best intentions: A Foucauldian examination on children's genuine participation in ICT design. Information Technology and People 28 (2015). Issue 2. https://doi.org/10.1108/ITP12-2013-0223

[39] Netta Iivari and Kari Kuutti. 2017. Critical design research and information technology: Searching for empowering design. DIS 2017 - Proceedings of the 2017 ACM Conference on Designing Interactive Systems. https://doi.org/10.1145/ 3064663.3064747

[40] Netta Iivari and Kari Kuutti. 2018. Critical design in interaction design and children - Impossible, inappropriate or critical imperative? IDC 2018 - Proceedings of the 2018 ACM Conference on Interaction Design and Children. https://doi.org/ $10.1145 / 3202185.3202773$

[41] Netta Iivari, Leena Ventä-Olkkonen, Sumita Sharma, Tonja Molin-Juustila, and Essi Kinnunen. 2021. CHI Against Bullying. Accepted for publication in CHI2021 (2021).

[42] Ole Sejer Iversen and Christian Dindler. 2013. A Utopian agenda in childcomputer interaction. International fournal of Child-Computer Interaction 1 (2013). Issue 1. https://doi.org/10.1016/j.ijcci.2012.08.002

[43] Ole Sejer Iversen and Rachel Charlotte Smith. 2012. Scandinavian participatory design - Dialogic curation with teenagers. ACM International Conference Proceeding Series. https://doi.org/10.1145/2307096.2307109

[44] Ole Sejer Iversen, Rachel Charlotte Smith, and Christian Dindler. 2017. Child as protagonist: Expanding the role of children in participatory design. IDC 2017 - Proceedings of the 2017 ACM Conference on Interaction Design and Children. https://doi.org/10.1145/3078072.3079725 
[45] Nairruti Jani. 2018. Ethno-theatre: Exploring a narrative intervention for trafficking survivors. fournal of Human Behavior in the Social Environment 28 (2018) Issue 5. https://doi.org/10.1080/10911359.2018.1432439

[46] Louise B. Jennings, Deborah M. Parra-Medina, De Anne K.Hilfinger Messias, and Kerry McLoughlin. 2012. Toward a critical social theory of youth empowerment. https://doi.org/10.1300/J125v14n01_03

[47] Peter De Jong, Insoo Kim Berg, Ben Furman, and Antti Mattila. 2016. Ratkaisukeskeisen Terapian Oppikirja (3rd ed.). Lyhytterapiainstituutti Oy. (original Peter de Jong and Insoo Kim Berg. 2008. Interviewing for solutions (3rd ed.). Belmont, CA: Thomson Higher Education.).

[48] Jonathan Lukens and Carl DiSalvo. 2011. Speculative Design and Technological Fluency. International fournal of Learning and Media 3 (2011). Issue 4. https: //doi.org/10.1162/ijlm_a_00080

[49] Sus Lyckvi, Virpi Roto, Elizabeth Buie, and Yiying Wu. 2018. The role of design fiction in participatory design processes. ACM International Conference Proceeding Series. https://doi.org/10.1145/3240167.3240258

[50] Deborah Maxwell, Toby Pillatt, Liz Edwards, and Rachel Newman. 2019. Applying Design Fiction in Primary Schools to Explore Environmental Challenges. Design fournal 22 (2019). Issue sup1. https://doi.org/10.1080/14606925.2019.1594972

[51] Maarten Van Mechelen, Bieke Zaman, Karin Slegers, Gavin Sim, Peggy Gregory, and Matthew Horton. 2014. Applying the CHECk tool to participatory design sessions with children. ACM International Conference Proceeding Series. https: //doi.org/10.1145/2593968.2610465

[52] Maria Menendez-Blanco, Pernille Bjern, and Antonella De Angeli. 2017. Fostering cooperative activism through critical design. Proceedings of the ACM Conference on Computer Supported Cooperative Work, CSCW. https://doi.org/10.1145/2998181. 2998198

[53] Oussama Metatla and Clare Cullen. 2018. "Bursting the assistance bubble": Designing inclusive technology with children with mixed visual abilities. Conference on Human Factors in Computing Systems - Proceedings 2018-April. https: //doi.org/10.1145/3173574.3173920

[54] Michael Muller and Q Vera Liao. 2017. Exploring AI Ethics and Values through Participatory Design Fictions. Human Computer Interaction Consortium (2017)

[55] Manuel Muñoz-Bellerín and Nuria Cordero-Ramos. 2020. The role of applied theatre in social work: Creative interventions with homeless individuals. British fournal of Social Work 50 (2020). Issue 5. https://doi.org/10.1093/bjsw/bcaa033

[56] Minna Orvokki Nygren and Sara Price. 2020. EPESonic: Understanding fictional framing of metaphorical actions in young children's digital interaction. Extended Abstracts - Proceedings of the 2020 ACM Interaction Design and Children Conference, IDC 2020. https://doi.org/10.1145/3397617.3402039

[57] Larissa Vivian Nägele, Merja Ryöppy, and Danielle Wilde. 2018. PDFi: Participatory Design Fiction with Vulnerable Users. In Proceedings of the 10th Nordic Conference on Human-Computer Interaction (NordiCHI '18). Association for Computing Machinery, New York, NY, USA, 819-831. https://doi.org/10.1145/3240167. 3240272

[58] Samiullah Paracha, Lynne Hall, Kathy Clawson, and Nicole Mitsche. 2020. Design, development, and usability of a virtual environment on moral, social, and emotional leaning. International fournal of Virtual and Personal Learning Environments 10 (2020). Issue 2. https://doi.org/10.4018/IJVPLE.2020070104

[59] Paul Coulton Paul, Rachel Jacobs, Dan Burnett, Adrian Gradinar, Matt Watkins, and Candice Howarth. 2014. Designing Data Driven Persuasive Games Address Wicked Problems Such as Climate Change. In Proceedings of the 18th International Academic MindTrek Conference: Media Business, Management, Content, and Services. Association for Computing Machinery, New York, NY, USA, 185-191. https://doi.org/10.1145/2676467.2676487

[60] Sebastian Prost, Elke Mattheiss, and Manfred Tscheligi. 2015. From awareness to empowerment: Using design fiction to explore paths towards a sustainable energy future. CSCW 2015 - Proceedings of the 2015 ACM International Conference on Computer-Supported Cooperative Work and Social Computing. https://doi.org $10.1145 / 2675133.2675281$

[61] Larissa Pschetz, Kruakae Pothong, and Chris Speed. 2019. Autonomous distributed energy systems: Problematising the invisible through design, drama and deliberation. Conference on Human Factors in Computing Systems - Proceedings. https://doi.org/10.1145/3290605.3300617

[62] Nuria Cordero Ramos and Manuel Muñoz Bellerin. 2019. Social work and applied theatre: creative experiences with a group of homeless people in the city of Seville. European fournal of Social Work 22 (2019). Issue 3. https://doi.org/10. 1080/13691457.2017.1366298

[63] Carolina Beniamina Rutta, Gianluca Schiavo, Massimo Zancanaro, and Elisa Rubegni. 2019. Comic-based digital storytelling with primary school children Proceedings of the 18th ACM International Conference on Interaction Design and Children, IDC 2019. https://doi.org/10.1145/3311927.3325331

[64] Carolina Beniamina Rutta, Gianluca Schiavo, Massimo Zancanaro, and Elisa Rubegni. 2020. Collaborative comic-based digital storytelling with primary school children. Proceedings of the Interaction Design and Children Conference, IDC 2020. https://doi.org/10.1145/3392063.3394433

[65] Nitin Sawhney. 2009. Voices beyond walls: The role of digital storytelling for empowering marginalized youth in refugee camps. Proceedings of IDC 2009
- The 8th International Conference on Interaction Design and Children. https: //doi.org/10.1145/1551788.1551866

[66] Phoebe Sengers, Kirsten Boehner, Shay David, and Joseph Kaye. 2005. Reflective design. Critical Computing - Between Sense and Sensibility - Proceedings of the 4th Decennial Aarhus Conference. https://doi.org/10.1145/1094562.1094569

[67] Bernd Carsten Stahl. 2008. Information systems: Critical perspectives. Routledge. https://doi.org/10.4324/9780203927939

[68] Marie Louise Juul Søndergaard and Lone Koefoed Hansen. 2018. Intimate futures: Staying with the trouble of digital personal assistants through design fiction. DIS 2018 - Proceedings of the 2018 Designing Interactive Systems Conference. https: //doi.org/10.1145/3196709.3196766

[69] Theresa Jean Tanenbaum. 2014. Design Fictional Interactions: Why HCI Should Care about Stories. Interactions 21, 5 (2014), 22-23. https://doi.org/10.1145/ 2648414

[70] Hakan Usakli. 2015. Enhancing Social Emotional Learning: Drama with Host and Refugee Children in Turkey. The International fournal of Human and Behavioral Science 1 (2015). Issue 2. https://doi.org/10.19148/ijhbs.12003

[71] Richmond Y. Wong and Deirdre K. Mulligan. 2016. When a product is still fictional: Anticipating and speculating futures through concept videos. DIS 2016 - Proceedings of the 2016 ACM Conference on Designing Interactive Systems: Fuse. https://doi.org/10.1145/2901790.2901801

[72] Michael Wrentschur and Michaela Moser. 2014. 'Stop: Now we are speaking!'A creative and dissident approach of empowering disadvantaged young people. International Social Work 57 (2014), 398-410. Issue 4.

[73] Yiying Wu, Sus Lyckvi, and Virpi Roto. 2019. 'What is fair shipping, anyway?' Using design fiction to raise ethical awareness in an industrial context. Conference on Human Factors in Computing Systems - Proceedings. https://doi.org/10.1145/ 3290605.3300666

[74] Johanna Ylipulli, Jenny Kangasvuo, Toni Alatalo, and Timo Ojala. 2016. Chasing digital shadows: Exploring future hybrid cities through anthropological design fiction. ACM International Conference Proceeding Series 23-27-October-2016. https://doi.org/10.1145/2971485.2993923

[75] Emily York and Shannon N. Conley. 2020. Creative Anticipatory Ethical Reasoning with Scenario Analysis and Design Fiction. Science and Engineering Ethics 26 (2020), 2985-3016. Issue 6.

[76] Sue Young. 2016. Ratkaisukeskeinen lähetymistapa koulukiusaamiseen (3rd ed.). (Original Sue Young. Solutions for Bullying in Primary Schools. In Peter de Jong and Insoo Kim Berg. 2008. Interviewing for solutions (3rd ed.). Belmont, CA: Thomson Higher Education, 308-318.). 287-296 pages. 